\title{
La falla "probada" del servicio médico-asis- tencial: ¿vislumbre del retroceso del Con- sejo de Estado?
}

\section{The Faulire of the Medical Care Service*}

\author{
Mónica LuCía Fernández Muñoz**
}

Fecha de recepción: 1 de abril de 2009

Fecha de aprobación: 30 de abril de 2009

\section{Resumen}

El favorecimiento del paciente, en términos probatorios, dentro de los procesos de responsabilidad médica, ha generado un gran número de críticas que al parecer están llevando a que el Consejo de Estado colombiano intente modificar las reglas generales que han regido durante casi quince años y cuyo abandono significaría no sólo desconocer el importante avance jurídico logrado, sino también alejarnos de los modernos desarrollos mundiales que en materia de responsabilidad propenden a la consagración de fórmulas de protección de la persona. En el presente artículo se esbozan algunas motivaciones que, rechazando el abandono de las normas tradicionales, justifican continuar por esta senda que en consonancia con nuestra realidad resulta ser la más apropiada.

\section{Palabras clave}

Responsabilidad médica, responsabilidad del Estado, culpa, presunción, protección al paciente, prueba de la culpa, onus probandi, faute virtuelle, res ipsa loquitur.

1 Este artículo corresponde al resultado de una investigación llevada a cabo en el marco de la Maestría en Derecho Contractual Público y Privado y se encuentra inserta dentro de la línea de investigación Derecho Privado, perteneciente al Grupo de Investigación Estudios en Derecho Privado de la Facultad de Derecho de la Universidad Santo Tomás.

2 Ph. D. (Becaria) en Persona y Tutelas Jurídicas por la Scuola Superiore di Studi Universitari e di Perfezionamento Sant’Anna di Pisa (Italia). Abogada de la Universidad del Cauca. Especialista en Responsabilidad y Daño Resarcible de la Universidad Externado de Colombia. Tutora de la Maestría en Derecho Contractual Público y Privado de la Universidad Santo Tomás. Docente Universitaria. Correo electrónico: monicafernanadez@ usantotomas.edu.co 


\begin{abstract}
The fact of favoring a patient, during the period allowed for the submission of evidence, within processes of medical responsibility, has generated an important number of critics that have had as a consequence the will of the Colombian State Council to modify general policies that have been valid for almost 15 years. Abandoning these policies will be considered ignorance towards previous legal steps forwards conquered, and moving further away form modern and developed global trends in responsibility issues that protect the individual person. The following article describes some motivations that don't reject the turn down of traditional norms, and justify why it is important to continue the actual trend that is most suitable to our reality.
\end{abstract}

\title{
Key words
}

Medical responsibilities, State responsibility, guilt, presumptuousness, patient protection, guilt proof, onus probandi, faute virtuelle, res ipsa loquitur,

\section{INTRODUCCIÓN}

Las reglas que rigen la responsabilidad médica constituyen uno de los ámbitos que mayor discusión genera y ha generado a lo largo de muchos años no sólo en Colombia, sino también en el ámbito mundial. En nuestro país, para el caso específico del régimen de responsabilidad médica aplicable al ámbito público, algunas de las decisiones del Consejo de Estado en los últimos dos años permiten percibir una intención de cambio por parte de esta doctrina jurisprudencial. En efecto, desde $1992 \mathrm{el}$ Alto Tribunal de lo Contencioso-administrativo era unánime en su posición en cuanto a la aplicación de la teoría de la falla "presunta" del servicio médico-asistencial, en razón a la consideración que, en términos de prueba, el paciente se encontraba en una posición de inferioridad, debido a los múltiples inconvenientes que para él significaba demostrar la culpa o falla de la administración cometida y en el criterio de mayor facilidad para la parte médica, en cuanto a la aportación de las pruebas necesarias para el establecimiento de la responsabilidad en juicios de esta naturaleza; es decir, se aceptaba la evidente posición de desigualdad en que se encuentran el paciente, lego e ignorante en materia médica y el médico, experto en dichas artes, a quien a la hora de acreditar determinados extre- mos de hecho, a menudo, de carácter científico, le resulta más fácil, es decir, más eficiente, porque ya tiene la información de lo realmente sucedido, sabe lo que hizo y cómo lo hizo, quiénes intervinieron, qué tratamientos o aparatos se emplearon, etc. Una doctrina ampliamente aplaudida en el ámbito nacional e internacional, si se tiene en cuenta que con ella se rechazaba otra forma de desigualdad, la cual se refiere a la de imponer la carga de la prueba a una parte a quien le resulta muy difícil o imposible conseguirla. Una carga que en el fondo podía legitimar el triunfo de aquella parte que valiéndose de maniobras logra que a la otra le resulte imposible probar un hecho.

Por tanto, en concordancia con los últimos avances mundiales del derecho de la responsabilidad, que buscan la protección de la parte débil, de la parte en posición de desigualdad, de inferioridad, se encuadraba esta doctrina jurisprudencial de nuestro máximo tribunal de lo contencioso-administrativo, la cual fue elaborada luego de varios años de análisis y reflexiones. Sin embargo, a partir de 2007 haIlamos algunas decisiones del Consejo de Estado que dejan entrever un posible cambio de postura; en efecto, frente al régimen de falla aplicable en 
el ámbito de la responsabilidad médica, manifiesta que si bien a partir de 1992 se aceptó un régimen de falla presunta, en virtud de criterios de equidad procesal y en contraposición a la teoría de falla probada aplicada hasta ese momento, dicho régimen es de aplicación meramente "excepcional", cuando se "acredite" que por los conocimientos técnicos y científicos requeridos, la carga de probar la falla en cabeza del demandante, le resulte excesivamente onerosa, por la dificultad y hasta la imposibilidad de la prueba. En consecuencia, según el razonamiento de esta corporación, por regla general, será el demandante quien deberá probar los extremos de la responsabilidad, salvo la excepción mencionada.

Este criterio, censurable desde varios puntos de vista y que prácticamente acaba con la evolución lograda hasta el momento, es el que ha impulsado la presente investigación, la cual tiene como objeto determinar si en verdad esta nueva posición constituye un indicio del retroceso de la corporación. Para poder responder este interrogante se ha considerado partir de los antecedentes para la construcción de la teoría de la falla del servicio; luego vamos a abordar el periodo de consolidación de la aplicación general de la teoría de la falla presunta del servicio al ámbito médico-hospitalario, y pasando luego a la revisión de las últimas tendencias antes mencionadas, a fin de poder analizar qué es lo que realmente está sucediendo, si efectivamente se puede hablar de una "decadencia" de la teoría de la falla presunta del servicio médico, o si, por el contrario, todo se explica por específicas concepciones de la presunción como método de prueba, que en la práctica han abierto paso a la aplicación de otras clases de razonamientos deductivos, establecidos inadecuadamente como una "presunción", pero que llevan, igualmente, a la definición de los hechos probados y que podrían explicar ese "miedo a las presunciones" que existe por parte del juzgador, ese temor a afirmar de manera expresa que, mediante presunciones se tiene determinado hecho por probado.
Finalmente, en aras de apoyar aún más la postura de que nuestro país no puede permanecer inmóvil y rezagado frente al latente y enorme desarrollo del derecho de la responsabilidad a nivel mundial, se esboza en términos muy generales algunos de los avances en este ámbito, en el cual claramente se puede observar la superación de la discusión frente a la consagración de nuevas formas protectoras para la parte débil, para la parte en situación de inferioridad, que para el caso específico, viene a estar representada por el paciente-víctima de daños médicos.

\section{ESPLENDOR DE LA TEORÍA DE LA FALLA PRESUNTA DEL SERVICIO MÉDICO}

\section{Antecedentes para la construcción de la teoría de la falla del servicio}

Recordemos que en Colombia el régimen de responsabilidad patrimonial del Estado responde a una construcción eminentemente jurisprudencial, lograda luego de un largo proceso. En efecto, desde finales del siglo XIX y hasta el año 1964, los procesos de responsabilidad de la administración pública fueron competencia de la Corte Suprema de Justicia, la cual declaraba dicha responsabilidad con fundamento en los arts. 2347, 2349 y 2356 del Código Civil; no obstante, desde 1939 se pronunciaba a favor de la estructuración de un sistema de responsabilidad del Estado, que estuviera fundamentado en principios del derecho público (esencialmente la teoría del servicio público), debido a la incongruencia derivada de la aplicación de normas civiles a esta materia (1939).

Hacia 1960, con fundamento en los arts. 16, 20 y 33 de la Constitución de 1886 y algunos del Código Contencioso Administrativo, el Consejo de Estado reclamó abiertamente la construcción de un sistema jurídico autónomo que dejara inoperantes para ese efecto las reglas del derecho privado (1960). Este paso definitivo fue dado por la Corte Suprema de Justicia en 1962 a través del fallo de Casación del 30 junio de ese año, con el que deci- 
dió abandonar de manera definitiva el criterio de la responsabilidad indirecta del Estado y la teoría organicista, para así adoptar en su lugar un régimen de responsabilidad directa del Estado basado en la denominada "falla del servicio" extensible no sólo a los casos en que la administración obrara a través de sus agentes, sino también, a aquéllos en los cuales actuara por conducto o en cabeza de cualquiera de sus servidores, sea cual fuere su posición jerárquica. Tesis con fundamento positivo en los arts. 16 de la Constitución de 1886 y 2341 del Código Civil, la cual se caracterizaba por el deber primario del Estado de suministrar a los asociados los servicios públicos, es decir, los medios conducentes a la efectividad de sus derechos y la realización cierta de los fines del Estado.

Así pues, con la expedición del Decreto 528 de 1964 la competencia general para conocer estos asuntos se trasladó al Consejo de Estado, el cual consolidó definitivamente la noción de falla del servicio. Posteriormente, el art. 90 fue incluido en la Constitución de 1991 con el argumento de que era absolutamente indispensable llenar el vacío de la Constitución de 1886, el cual consistía en no haber señalado, por medio de una cláusula general, la responsabilidad patrimonial del Estado. Sin embargo, como en su momento lo afirmó la misma Corte Suprema de Justicia (1962), ello resultaba innecesario, pues la inexistencia de un texto legal que estatuyera concretamente la responsabilidad aquiliana de las entidades jurídicas y, especialmente, la de administración por las fallas del servicio, no fue óbice para que con aplicación de la ley de la analogía se abriera sitio en las disposiciones del derecho común, señalando de ese modo el camino de la justicia y el perfeccionamiento de la jurisprudencia; es decir, ni la Corte Suprema de Justicia ni el Consejo de Estado habían necesitado de un texto constitucional o legal para estructurar y desarrollar un completo sistema de responsabilidad patrimonial del Estado.

A propósito de la consagración del art. 90 de la Constitución Política de 1991, algunos doctrinantes manifestaron su criterio a favor de la construcción de una responsabilidad objetiva en ámbito médicohospitalario, en el cual se consideraba que esta norma estipulaba un principio general de responsabilidad patrimonial del Estado, trayendo como fundamento único y exclusivo el denominado daño antijurídico, que consagraba un régimen objetivo de responsabilidad, al excluir toda imputación de carácter subjetivo.

Según los defensores de esta doctrina, la aplicación estricta de la noción daño antijurídico, permitía prescindir de la clasificación de las obligaciones de medio y de resultado, que exigía una responsabilidad basada en la culpa y en su lugar aplicar este nuevo régimen objetivo de responsabilidad del Estado, en el cual sólo el daño constituye la fuente de la obligación indemnizatoria, desplazando el fundamento de la responsabilidad administrativa, del concepto subjetivo de antijuridicidad de la conducta al concepto objetivo de antijuridicidad del daño (Sarmiento, 2001). Según este criterio, el elemento subjetivo relacionado con la conducta de la administración desaparece, en consecuencia, para atribuir la responsabilidad se debe apreciar la relación de causalidad material y objetiva entre hecho generador y el daño, es decir, la acción o la omisión se debe apreciar desde un punto de vista material y objetivo, no como una falta o una culpa.

No obstante el anterior planteamiento, otro sector de la doctrina se opuso a la extensión de este régimen de responsabilidad objetiva no sólo al ámbito médico, sino también a todos los sectores en los que pudiera resultar involucrada la responsabilidad del Estado. En términos generales, su oposición reposó no sólo en el análisis de los antecedentes normativos del citado art. 90 constitucional, sino también, en las justificaciones que se dieron para incluir esta nueva norma en el texto de la Constitución Política de 1991.

En efecto, según este sector, al contrario de la consagración de un régimen general de respon- 
sabilidad objetiva del Estado (Navia, 2000), en aplicación de las normas que sirvieron de fuente normativa de nuestro art. 90, es decir, el art. 106 núm. 2 de la Constitución española de 1978, que estatuye el derecho de los particulares a obtener una reparación por la lesión sufrida con ocasión del funcionamiento de los servicios públicos, y el art. 21 de la Ley española de expropiación forzosa de 1954, que consagra el derecho a la indemnización de toda lesión que resulte del funcionamiento normal o anormal de los servicios públicos, la jurisprudencia sostuvo inicialmente que la responsabilidad del Estado era de corte objetivo; sin embargo, con el paso del tiempo, tanto ella como la doctrina dejaron de ser unánimes y se consideró que el régimen objetivo de la ley de expropiación no debía ser extendido a todas las hipótesis de lesión, dado que en otros casos era necesario establecer la falla del servicio. En la actualidad, la responsabilidad del Estado español no es siempre objetiva, siendo múltiple su fundamento.

Por otra parte, de acuerdo con las justificaciones que en términos generales se dieron para incluir el art. 90 en el texto de la Constitución Política de 1991, es decir, fundamentar la responsabilidad del Estado en los criterios de antijuridicidad del daño e imputabilidad, a fin no sólo de ampliar el ámbito de la responsabilidad del Estado, dándole cabida a nuevos tipos, diferentes al de la responsabilidad fundamentada en la falla del servicio, sino también de exigir que no basta con la relación de causalidad material entre el daño y el agente que lo produce, sino que es además indispensable que dicho daño sea jurídicamente atribuible (causalidad jurídica) (Lleras \& Tangarife, 1996), de este modo, entonces, los autores concluyeron que estas justificaciones no agregaban nada nuevo al sistema de responsabilidad estatal que ya había sido construido gracias a la asidua labor de la jurisprudencia nacional, resultando de ello que el verdadero alcance buscado con la inclusión de esta norma no era otro que darle rango constitucional a la responsabilidad patrimonial del Estado, lo cual, según su criterio, resultaba inútil teniendo en cuenta que la jurisprudencia ya había llegado a los mismos resultados sin necesidad de recurrir a una norma constitucional especial.

Así pues, frente a esta disyuntiva en las posiciones doctrinales, la jurisprudencia de la Corte Constitucional (1996), al percatarse del enorme impacto económico que generaba la objetivación de la responsabilidad estatal, sentó su criterio manifestando que la figura del "daño antijurídico" se subsumía en cualquiera de los regímenes tradicionales de responsabilidad del Estado, de acuerdo con los cuales, para algunos casos se exigía la prueba de la culpa, en otros, dicha culpa se presumía y para otros la ruptura de la igualdad ante las cargas públicas podía configurar una responsabilidad objetiva. En consecuencia, el hecho de que el artículo 90 fuera el fundamento constitucional de la responsabilidad patrimonial del Estado, no significaba que los regímenes fueran idénticos en todos los eventos.

Desde esta perspectiva, el Consejo de Estado ha desplegado de la noción general de "daño antijurídico" dos conceptos distintos, "daño antijurídico subjetivo" y "daño antijurídico objetivo", a fin de hacer referencia, en el primero, a la "antijuridicidad de la conducta de la administración" para aplicar el régimen subjetivo de la responsabilidad y en el segundo, a la "antijuridicidad del daño", con el objeto de aplicar el régimen de responsabilidad objetiva, en ciertos eventos. Sin embargo, a pesar de esta construcción, se debe destacar que el Consejo de Estado continúa proclamando la "falla del servicio" como principal título de imputación y regla general de la responsabilidad del Estado (Suescún, 2004). De este modo, la responsabilidad por falla del servicio, corresponde a una especie de responsabilidad que nace de una falla funcional $u$ orgánica, la cual encuentra su fundamento en un servicio o función que el Estado debe cumplir por disposición de la ley. 
En este evento, el problema de la culpa personal del funcionario desaparece para darle campo a la falla o culpa anónima del servicio, la cual juega un rol de "pantalla protectora para el funcionario" (Guettier, 2003), protección justificada por la voluntad de evitar que un compromiso demasiado sistemático de su responsabilidad contribuya a paralizar su acción, ubicada bajo el signo del interés general y, además, por la relación de subordinación estrecha en que se halla, en la cual la función pública lo somete a ciertas obligaciones inducidas por las necesidades del servicio público, de las que es posible deducir una cierta pérdida de libertad, que, a su vez, entraña para el agente una disminución de su propia responsabilidad, incluso un desvanecimiento cuando se encuentra en el ejercicio de sus funciones. De este modo, el juez administrativo ignora voluntariamente al agente-autor y tiene en cuenta a la persona pública misma como aquélla que ha cometido la falla de la que la víctima reclama reparación.

Para el evento específico de la responsabilidad médica, el Consejo de Estado ha sentado su posición considerando que el régimen riguroso de responsabilidad objetiva no es aplicable al cumplimiento de obligaciones de medio, como las del médico, en las cuales no cabe la declaratoria de responsabilidad desde la perspectiva del daño antijurídico (Suescún, 2004). De este modo, la falla sólo es aplicable a la entidad prestataria del servicio médico-asistencial y no al profesional médico mismo causante del daño, perdiendo la culpa su individualidad, pues ésta no es predicable de un funcionario en particular, sino que se imputa al servicio, en general. En el evento de producirse un daño derivado de la prestación del servicio público de salud, se procede, entonces, a aplicar el régimen subjetivo de la responsabilidad extracontractual del Estado, atendiendo a las obligaciones de medio como regla general (1992; 2000; 1997; 1999), perjuicio cuya indemnización debe reclamarse a partir del ejercicio de la acción de reparación directa.
Entre el médico y el paciente la relación que se establece está regida por el derecho administrativo o derecho público, que regula las relaciones entre los agentes de la administración y los usuarios del servicio público. En este caso específico, el paciente (ciudadano común) acude ante la entidad de salud del Estado, en su calidad de usuario de un servicio público. El paciente se encuentra aquí dentro de una situación legal y reglamentaria con el médico, una relación estatutaria (Moatti, 1988), cuya principal consecuencia la constituye el hecho de que el médico no responde frente al paciente por los daños ocasionados con su actividad, salvo que se trate de una culpa "personal" desligada del servicio, sino que es la administración la que entra a responder por sus agentes en caso de falla del servicio, es decir, se genera una responsabilidad directa de la administración considerada, en este caso, como única responsable de los cuidados prestados dentro de sus instalaciones públicas de salud y por sus agentes. La falla del servicio constituye una noción particularmente amplia que logra incluir bajo la denominación falla anónima del servicio, aquellos eventos en los que no logra identificarse un autor.

Este sistema resulta beneficioso no sólo para la víctima, dada la posibilidad de procurarse un deudor más solvente, sino también para el médico (agente público), quien constatará las condenas impuestas a cargo de la entidad, garantizadas por su aseguradora y quien estará en una posición más ventajosa con respecto al médico que ejerce en el sector privado (Fernández, 2008).

\section{Consolidación de la teoría de la falla presunta aplicable a los casos de responsabilidad médico-asistencial}

Para el campo específico de la responsabilidad por la prestación del servicio médico-asistencial, nuestro máximo tribunal de lo contencioso-administrativo resolvió adoptar la teoría de la falla presunta del servicio. A través del conocido fallo 
del 30 julio de 1992, con ponencia del magistrado Daniel Suárez, el Consejo de Estado marcó un hito en esta materia.

Sin embargo, recordemos que la formulación del régimen de la falla presunta no fue realizada de manera intempestiva, sino que fue el producto de una evolución en la que la exigencia inicial a la víctima de la demostración de la falla del servicio empezó a controvertirse hasta llegar a presumirse. Fue, entonces, que la jurisprudencia empezó, poco a poco, a establecer un menor rigor probatorio en materia de falla médica (Peláez, 2003, 2001).

En efecto, en una primera etapa el Consejo de Estado coincidió con la posición de la Corte Suprema de Justicia, ya que manejaba la responsabilidad médica bajo el concepto de falla probada del servicio y dentro del marco de las obligaciones de medios (1987; 1992). En consecuencia, con sujeción a este esquema, el demandante corría con la carga de probar la falla del servicio (es decir, que el servicio funcionó mal o tardíamente o no funcionó), el perjuicio causado y la relación de causalidad entre aquélla y éste, es decir, que la falla había sido la causa eficiente del daño sufrido por la parte demandante, pues se trata de una obligación de medios, de la sola existencia del daño, por ende, no se puede presumir la falla del servicio, por tanto, era necesaria su demostración por parte del actor, conforme a lo consagrado en el art. 177 del CPC.

En 1990 este esquema comenzó a sufrir algunas variaciones. La situación de injusticia que se evidenciaba al imponer al demandante la carga de probar la culpa médica, requería del establecimiento de una presunción que pudiera invertir tal carga. Desde ese entonces, para los servicios médicos de carácter oficial, se empezó a concebir una falla del servicio presunta, fundamentada, por una parte, en la constatación de la mayor facilidad de acceso a la prueba de los hechos por parte del médico; por otra parte, en razones de justicia y equidad.
Es el fallo del 24 octubre de 1990, con ponencia del magistrado Gustavo De Greiff, el cual paradójicamente, por manejar principios, normas y fundamentos del derecho privado, sirvió de punto de reflexión y posibilitó el avance, surgimiento y consagración de la teoría de la falla presunta en la actividad médica estatal, como reflejo de la autonomía e independencia frente al derecho civil (Gil, 1995). La presunción de falla que con esta jurisprudencia se acogió, fundamentada en el art. 1604 CC y aunque no muy clara en cuanto a la aplicación de la norma a la tesis de la responsabilidad del Estado por falla en la prestación del servicio de salud, propia del derecho público, fue reiterada posteriormente en la citada decisión del 30 julio de 1992, pero con una fundamentación jurídica diferente, la cual hizo referencia a la mayor posibilidad en que se encuentran los profesionales de satisfacer las inquietudes y los cuestionamientos que se formulan contra sus procedimientos.

Así pues, el paso hacia la teoría de la falla presunta fue sustentado en la desigualdad que significaba imponer la carga de la prueba precisamente a la parte que le resultaba más difícil conseguirla. En el marco del principio de igualdad en relación con la carga de la prueba, se debía entonces tener en cuenta a cuál de las dos partes le quedaba más fácil probar un hecho determinado.

Con el reconocimiento de esta presunción de culpa, se produjo lo que generalmente se ha denominado como inversión de la carga de la prueba del elemento culpa, según la cual, corresponde a la entidad demandada y no al demandante, lego e ignorante en estas cuestiones, demostrarlo. Dijo el Consejo de Estado en esa oportunidad (1992), lo siguiente:

Por regla general le corresponde al actor la demostración de los hechos y cargos relacionados en la demanda. Sin embargo, con mucha frecuencia se presentan situaciones que le hacen excesivamente difícil, cuando no imposible, las comprobaciones respectivas, tal es el caso de las 
intervenciones médicas, especialmente quirúrgicas, que por su naturaleza, por su exclusividad, por la privacidad de las mismas, por encontrarse en juego intereses personales o institucionales, etc., en un momento dado se constituyen en barreras infranqueables, para el paciente, para el ciudadano común obligado procesalmente a probar aspectos científicos o técnicas profesionales [...].

Sin duda, resultaría más beneficioso para la administración de justicia en general, resolver esta clase de conflictos, si en lugar de someter al paciente o sus familiares, a la demostración de las fallas en los servicios y técnicas científicas prestadas por especialistas, fueran éstos, los que por encontrarse en mejores condiciones de conocimiento técnico y real por cuanto ejecutaron la respectiva conducta profesional, quienes satisfacieran [sic] directamente las inquietudes y cuestionamientos que contra sus procedimientos se formulan [...]

Podrán así los médicos exonerarse de su responsabilidad y con ellos los centros clínicos oficiales, mediante la comprobación, que para ellos, se repite, es más fácil y práctica, de haber actuado con la eficiencia, prudencia o idoneidad requeridas por las circunstancias propias del caso concreto, permitiéndose al juzgador un mejor conocimiento de las causas, procedimientos, técnicas y motivos que llevaron al profesional a asumir determinada conducta o tratamiento.

Esta postura definitiva del Consejo de Estado fue la que llevó a la unificación de criterios en torno al tema, a través de la expedición de esta sentencia por el máximo Tribunal con la cual se decidió adoptar la tesis de la falla del servicio presunta. Con fundamento en esta teoría, la jurisprudencia reiterada del Consejo de Estado consideró que el demandante debía demostrar como mínimo los supuestos o antecedentes de hecho que permitieran la operancia de la presunción, pues es necesario recordar que la parte favorecida con una presunción tiene la carga de probar los supuestos de ésta (Rocha, 1941; Rocha, De la prueba en derecho, 1967). En consecuencia, se exigió que el demandante probara el daño sufrido y la relación de causalidad existente entre éste y la falla del servicio presunta, o lo que es lo mismo, "que se le prestó el servicio en tal fecha y que sufrió el daño cuya indemnización pretende" o "que la administración le prestó el servicio y que esa prestación le produjo un daño." Luego, el actor no tendría que demostrar la conducta omisiva o irregular de la administración, porque ésta se presumía.

Por otra parte, se consideró que dicha presunción se podía desvirtuar por parte de la entidad demandada a través de la prueba de la diligencia y cuidado o la existencia de un elemento extraño que rompiera el nexo de causalidad (fuerza mayor, culpa exclusiva de la víctima o hecho exclusivo o determinante de un tercero) (Hoyos, 1999), pues, en efecto, se debe tener en cuenta que si bien la presunción se funda en probabilidades, la más alta probabilidad de certeza no excluye la probabilidad de error, por ello, la deducción es siempre desvirtuable por prueba en contrario (salvo presunción de derecho), así pues, la persona a quien no le conviene la presunción, en este caso el demandado, debe dar la prueba en contrario para destruirla (Rocha, De la prueba en derecho, 1967).

Con base en lo anterior y según criterio del Consejo de Estado (1990)

[...] si de acuerdo con la naturaleza de la obligación transgredida por razón del hecho dañino fuente de la responsabilidad, el deudor sólo debía ser diligente y cuidadoso, la prueba de que lo fue implicará de suyo, obviamente, que no hubo un caso fortuito o una fuerza mayor que le hubiera impedido serlo. En cambio, si el deudor, también de acuerdo con la naturaleza de la obligación, debía entregar algo y no lo entregó o debía alcanzar un fin determinado y no lo alcanzó, es evidente, entonces, que lo único que podrá exonerarlo en tal caso, será la prueba del caso fortuito o la fuerza mayor, pues en tratándose de una obligación de esa clase no le basta con ser diligente y cuidadoso. 
El primer interesado en demostrar que su conducta fue diligente o cuidadosa debe ser la administración, pues un servicio debe prestarse en la forma prescrita por las leyes o los reglamentos y si ocurre que no se prestó o se prestó inoportunamente, la primera inferencia lógica del juzgador será que el funcionamiento anormal se debió, en principio, a culpa, es decir a negligencia o descuido de la administración.

En consecuencia, la no demostración de la diligencia, estando en capacidad de hacerlo, constituye la gran sospecha o la presunción de que fue precisamente la negligencia la que produjo el daño. En suma, se infiere que lo que la jurisprudencia decidió fue trasladar la carga de la prueba del paciente común y corriente, lego e ignorante en la ciencia médica, a quienes son expertos en ésta y sobre todo a quienes han llevado la parte activa en el comportamiento profesional censurado, en aquellos eventos en los que ocurren dificultades para la parte actora acerca de la conducta del ente demandado, debido a la falta de conocimiento profesional, técnico y especializado en la materia.

Sin embargo, es importante tener en cuenta que el Consejo de Estado (1997) concuerda con el criterio de la Corte Suprema de Justicia cuando señala que la prueba de la ausencia de culpa no puede ser nunca una prueba perfecta, en la medida en que con ella lo que se evidencia es simplemente que el daño no ha tenido origen en la falta; en consecuencia, probar la ausencia de falla no significa demostrar cuál fue concretamente la causa del daño recibido por el paciente. Así pues,

[...] la carga que incumbe a las entidades oficiales prestadoras de servicios médicos y que se les impone en desarrollo de la falla que en su contra se presume, se limita a demostrar que su conducta fue diligente y que el daño sufrido por la víctima no fue producto de inatención o de atención inadecuada.

Como se puede observar, la aplicación de teoría de la falla presunta del servicio y la inversión de la carga de la prueba en los procesos de reparación directa por mala praxis médica en las instituciones públicas de salud, se realizó en procura de la equidad y con el objeto de poner en un plano de equilibrio a las partes contendientes. Considerando que lo más conveniente era que el médico y la institución aportaran la prueba sobre la razón de la actividad médica realizada, por ser ellos quienes tenían mayores posibilidades de probar y explicar los procedimientos que se aplicaron.

Es necesario resaltar que esta solución acogida por el Consejo de Estado considera, por regla general, la obligación médica como obligación de medios, y, según la corporación, es en razón a dicha naturaleza que la entidad demandada puede demostrar que cumplió adecuadamente con su obligación, esto es, que obró diligentemente poniendo los medios a su alcance para la curación del enfermo. Gracias a que la obligación médica se sigue considerando de esta naturaleza, lo que se presume no es la responsabilidad, sino la falla del servicio, que se puede desvirtuar si se prueba un comportamiento adecuado o diligente. En tal entendido, la clasificación de las obligaciones (medios y resultado) no incide, entonces, en la prueba de la culpa a través de presunción.

\section{¿DECADENCIA DE LA TEORÍA DE LA FALLA PRESUNTA DEL SERVICIO MÉDICO?}

\section{Últimas tendencias del Consejo de Estado en la materia}

A partir de la aplicación de la teoría de la falla presunta del servicio médico-asistencial, un sector de la doctrina colombiana (Tamayo, 2003; Tamayo, Rapport colombien (I), 2003) comenzó a manifestar su preocupación por su uso "casi generalizado", produciendo lo que se denominó como inversión permanente del deber probatorio. La crítica se dirigió básicamente con respecto al paso de un régimen de falla probada a uno de falla presunta, aplicable en absolutamente todos los casos de 
daño causado en desarrollo de la prestación del servicio médico, lo cual significaba, en palabras de los opositores, lo mismo que "salir de una posición rígida a favor de los médicos, para caer en otra igualmente rígida a favor de las víctimas", es decir, se estaba continuando con la carga estática de las pruebas, pero esta vez a favor del demandante.

Empero, otro sector de la doctrina (Parra, 2004; Fernández, 2008), consideró que la inversión de la carga de la prueba que traía consigo la aplicación de la teoría de la falla presunta del servicio, no desconocía el derecho de defensa del médico o institución, por el contrario, le permitía expresar su opinión científica en relación con el caso, demostrando que la atención brindada se enmarcaba en los lineamientos de la lex artis y en los criterios de calidad exigidos para el ejercicio de la profesión. La inversión de la carga fue considerada como la mejor manera de acercar el juez a la noción de lo justo, pues le permitía conocer de primera mano el procedimiento realizado; del mismo modo, permitía ampliar el criterio de justicia en relación con el demandante, quien no tenía que inmiscuirse más en discusiones científicas.

El Consejo de Estado consideró, entonces, que al parecer la aplicación práctica de inversión de la carga probatoria no estaba cumpliendo los postulados originales de este principio, debido a que, en su generalidad, se estaba haciendo recaer toda la carga en el demandado, lo que denotaba como estática la carga del demandante y olvidaba que al juez le correspondía también esforzarse por conocer la realidad de los eventos, utilizando para ello los poderes que posee en materia de pruebas, todo con la finalidad de no perjudicar a la parte gravada con la inversión de la carga.

Por este motivo y ante las múltiples críticas elevadas al respecto, el Consejo de Estado (1999, 2000) aclaró que cuando se había consagrado el régimen de la falla presunta, lo había hecho a partir de fundamentos que consagraban el sistema de las cargas probatorias dinámicas, cuya aplicación, aunque sin sustento en nuestra legislación procesal pero con asidero en el principio constitucional de equidad, había llevado a plantearlo en términos tales que, de suyo, ponían en peligro su propio fundamento, pues en la práctica lo que se había hecho era simplemente proceder a invertir la carga de la prueba en todos los casos de daño causado en desarrollo de la prestación del servicio médico asistencial, exigiéndose siempre a las entidades públicas demandadas la prueba de que dicho servicio había sido prestado debidamente, para poder desvirtuar la presunción y exonerarse de responsabilidad.

Con el ánimo de replantear el régimen de la falla presunta, la corporación consideró que "no todos los hechos $y$ circunstancias relevantes para establecer si las entidades públicas obraron debidamente tienen implicaciones técnicas o científicas", luego, era preciso una tarea más ardua y exigente por parte del juzgador, quien tendría que valorar, en cada caso, si éstas circunstancias se encontraban presentes o no, pues, era posible hallarse frente a situaciones en las que es el paciente quien se encuentra en mejor posición para demostrar ciertos hechos relacionados con la actuación de la entidad demandada y allí era donde residía la explicación del dinamismo de las cargas probatorias, cuya aplicación, según el alto Tribunal, se hacía imposible ante el recurso "obligado" a la teoría de la falla del servicio presunta, con la que simplemente se producía una inversión "permanente" del deber probatorio. Así pues, la corporación resaltó la tarea del juez, quien en aplicación del principio de las cargas probatorias dinámicas, adquiría un papel protagónico, pues él era quien debía establecer, en cada caso, cuál de las partes se encuentra en condiciones más favorables para demostrar cada uno de los hechos relevantes, en relación con la conducta del demandado, a fin de adoptar una decisión.

Con posterioridad a esta sentencia, el Consejo de Estado precisó aun más su posición (2004; 2005), 
afirmando que la demostración de la falla en la prestación del servicio médico asistencial corre por cuenta del demandante, a menos que dicha carga probatoria resulte "extraordinariamente difícil o prácticamente imposible" y se torne "excesiva". Sólo en este evento y de manera excepcional, será procedente la inversión del deber probatorio, previa la inaplicación del artículo 177 del Código de Procedimiento Civil -que obligaría a la parte actora a probar siempre el incumplimiento por el demandado de su deber de prestar debidamente el servicio mencionado-, por resultar la regla en él contenida, para el caso concreto, contraria al principio de equidad, previsto en el artículo 230 de la Constitución Política.

En consecuencia, cuando la demostración de los hechos que estructuran la falla resulta prácticamente imposible para la víctima, es procedente, en estas condiciones, con fundamento en la equidad, como criterio auxiliar de la actividad judicial, acudir, de manera excepcional, a la inversión del deber probatorio de dicho elemento de la responsabilidad, inaplicando el art. 177 del CPC. Es decir, ante la dificultad para el paciente-víctima de acreditar los hechos en los cuales edifica sus pretensiones y ante la facilidad para la parte demandada de aportar dichos medios de prueba, el Consejo de Estado procede a la inaplicación del art. 177 CPC que consagra el principio de la carga de la prueba y exige que el demandante pruebe los extremos de la responsabilidad que demanda, por considerarlo contrario a la equidad para este caso concreto.

Tal como lo consagra la Corte Constitucional (2002), la aplicación de la equidad como criterio auxiliar de la actividad judicial, permite la corrección de la ley para evitar una consecuencia injusta no prevista por el legislador, dado que su función es evitar una injusticia como resultado de la aplicación de la ley a un caso concreto, esto permite una graduación atemperada en la distribución de cargas y beneficios a las partes y, en consecuencia, brinda justicia cuando la aplicación de la ley resultaría una injusticia, dadas las particularidades del caso por resolver. En suma, según criterio de la Corte, el principio constitucional de equidad, hace posible cuestionar e ir más allá de la igualdad de hecho que el legislador presupone, al actuar como elemento de ponderación, haciendo posible que el juez atribuya y distribuya proporcionalmente las cargas impuestas por la norma general, de acuerdo con aquellos elementos relevantes, que la ley no considera explícitamente.

Sin embargo, es importante saber que la equidad no exige un equilibrio perfecto, pues lo que repugna a este principio son las cargas excesivamente onerosas o el desentendimiento con respecto a una de las partes interesadas; la equidad es remedial, porque, en últimas, lo que busca es evitar la arbitrariedad y la injusticia, aquellas consecuencias injustas que se derivarían de la aplicación de una ley a una situación particular cuyas especificidades exigen una solución distinta a la estricta y rigurosamente deducida de la norma legal.

Así pues, de acuerdo con este replanteamiento, que según criterio del Consejo de Estado, no hace otra cosa que retomar el verdadero significado del principio de la carga dinámica de la prueba, se busca atenuar la inversión de la carga probatoria, estableciendo para ambas partes el deber de ejercer una actividad probatoria de manera equilibrada. Como antes se señaló, se trata de un régimen de aplicación eventual, excepcional, el cual debe considerar que no todos los hechos y las circunstancias relevantes para establecer si las entidades públicas obraron debidamente tienen implicaciones técnicas o científicas; sin embargo, es preciso analizar el criterio a partir del cual el Consejo de Estado hace depender la aplicación de la presunción, esto es, la excesividad para el demandante, es decir, la extraordinaria dificultad e imposibilidad práctica de aportar la prueba.

El alto Tribunal acierta cuando afirma que hay casos en los cuales lo que se debate no son justamente 
aspectos técnico-científicos, teniéndose que valorar si en ellos es el paciente quien se encuentra en mejor posición o le queda más fácil demostrar los hechos relacionados con la actuación de la entidad respectiva, por ejemplo, cuando lo que se debate es que el paciente no acató las recomendaciones del médico (negligencia del paciente), frente a este evento le resultará más fácil al paciente aportar la prueba de que sí cumplió con dichas recomendaciones, por ejemplo, con los recibos de compra de los medicamentos y con testimonios de personas que declaren que, en efecto siguió, todas las indicaciones dadas por el profesional de la medicina. Sin embargo, resulta que los procesos en los cuales sí se debaten aspectos técnico-científicos son la inmensa mayoría y es en los cuales mayor importancia debe cobrar la teoría de la falla presunta.

En consecuencia, la consagración de este "cambio de postulado", en suma, nada cambia la tradicional concepción, según la cual, cuando se debaten aspectos técnico científicos, el paciente se encuentra en una posición de inferioridad que hace deducir, desde un principio, que es al médico o a la entidad demandada a la cual, por su libertad de acceso a los medios de prueba, le queda más fácil aportar la prueba de los hechos fundamento del litigio.

Si se retoman las acertadas palabras del entonces H. Consejero de Estado Daniel Suárez:

[...] el problema no es de alta filosofía ni de alto contenido intelectual. Es simple cuestión de lógica, de ver qué es lo normal y qué es lo anormal. Lo normal es que sea el médico quien explique: yo obré de tal manera, porque así lo dispone la ciencia médica, eso es lo que se acostumbra, ordené que se le aplicara tal medicamento con tal periodicidad porque esto es lo que se está utilizando; o esto es lo que he averiguado últimamente desde el punto de vista científico; o explicar por qué no se hizo una intervención quirúrgica sino que se procedió a efectuar otro tratamiento, cuáles eran los riesgos en caso de intervenir, etc. (Suárez, 1997).
Tal como el propio Consejo de Estado (2005), en sus mejores épocas, lo aseveraba:

[...] es indudable que el experto (médico) y el profano (paciente) no se encuentran en pie de igualdad a la hora de acreditar determinados extremos de hecho (a menudo, de carácter científico), y que, al menos en vía de principio, parece más fácil para el primero la aportación de las pruebas necesarias. $\mathrm{O}$, en todo caso, es muy probable que el médico pueda hacerlo de manera más eficiente, porque ya tiene la información de lo realmente sucedido, sabe lo que hizo y cómo lo hizo, quiénes intervinieron, qué tratamientos o aparatos se emplearon.

Toda esta esmerada construcción que le llevó al alto Tribunal de ese entonces, muchos años de análisis y dedicación, al parecer está tratando de ser desmontada, por el actual Consejo de Estado, desde que ha empezado a pregonar con aguda insistencia el abandono de la teoría de la falla presunta del servicio médico-asistencial como principio general, para aplicarlo sólo de manera excepcional. En algunos de sus últimos fallos $(2007,2008)$ el máximo Tribunal de lo contencioso administrativo acentúa que no se trata de invertir automáticamente la carga de la prueba para dejarla a la entidad hospitalaria, pues el demandante debe probar los tres elementos de la responsabilidad. Una posición abiertamente contraria a los postulados de justicia que reclaman un mejor tratamiento para la parte en situación de inferioridad.

Se espera que la aplicación de este régimen llamado hoy "excepcional" se convierta en la práctica en la generalidad, teniendo en cuenta que en la mayoría de este tipo de procesos lo que se discuten son asuntos técnico-científicos que de suyo, en la casi totalidad de los casos, hacen "extraordinariamente difícil", sino "prácticamente imposible" demostrar los elementos constitutivos de la responsabilidad, sin hablar de las dificultades que se enfrentan al momento de integrar la prueba, tema que daría para otro espacio de discusiones; 
y, contando además con que el juez puede tener probados los hechos a través de los distintos indicios que pueda evaluar en el proceso.

No basta con que el juzgador se excuse en que "no se han precisado las especiales circunstancias probatorias de carácter técnico o científico que hacen imposible y excesivo para el demandante cumplir con su deber de aportar la prueba de la falla médica" (2007); pues, sinceramente, resulta muy difícil que se llegue al final de un proceso sin que el juez no haya podido razonar o deducir la falla del servicio, llegando por esta vía a la presunción (Carrasco, 2006). En realidad al juez le es suficiente la percepción de los hechos, en muchos casos concluyentes por sí solos, para presumir la conducta médica culposa, en este caso, la falla en la prestación del servicio médico-asistencial, para imputar la responsabilidad, "presumiendo" certeramente el carácter defectuoso de la actividad (Díaz-Regañón, 1996).

Es razonable que continuemos por la senda de la presunción, pues de ordinario el paciente no tiene medios directos para precisar las actuaciones médicas y sanitarias, muchas veces incluso ignora en qué consistió su actuación, igualmente, como arriba se indicó, le resulta difícil aportar las pruebas necesarias, muchas veces por la falta de colaboración e incluso oposición de médicos y centros hospitalarios. A este respecto, hay quienes afirman que "no se puede caer en falsos espejismos puesto que en relación con la prestación de servicios asistenciales por el Estado, sigue siendo éste a quien le corresponde probar la diligencia y cuidado respecto de aspectos científicos y técnicos" (Peláez, 2003). Además, se debe prevenir la posibilidad de que con la aplicación generalizada del régimen de la falla probada del servicio, la parte demandada asuma una posición pasiva, no haciendo absolutamente nada en el periodo probatorio, esta actitud también justifica el reproche a la pretensión del Consejo de Estado de ampararse en el principio del onus probandi que obliga al demandante a probar los hechos que conforman el supuesto de hecho de la norma cuya aplicación solicita, para negarse a decretar una presunción.

A este respecto, es necesario recordar que la función del principio de la carga de la prueba es permitir al juez resolver el caso cuando las pruebas no ofrecen suficiente apoyo para la decisión, cuando los hechos no han sido probados. Las reglas sobre la carga de la prueba

[...] son un puente entre la situación de
falta de prueba de los hechos y la aplica-
ción de la norma sustantiva que rige el
caso, porque evitan que el juez decida in-
debidamente la causa aplicando la norma
sustantiva en una situación en la que no
podría ser aplicada (Taruffo, 2008).

En efecto, si no se ha probado un hecho principal, no se puede aplicar la norma sustantiva que asume ese tipo de hecho como una premisa fáctica, en consecuencia, las pretensiones basadas en ese hecho deben ser rechazadas, pero, se debe tener en cuenta, en consonancia con la destacada doctrina, que en este caso la parte que tenía la carga de probar el hecho perderá, porque no se ha satisfecho la carga de prueba, no la carga de presentar pruebas, ya que la estructura del proceso en los sistemas de civil law permite que el juez ordene de oficio la presentación de pruebas, luego, "hablar de una carga de presentación de pruebas en el curso del proceso puede parecer irrelevante" (Taruffo, 2008).

El principio de la carga de la prueba se aplica en el momento en que se toma la decisión final y determina cómo hacerlo; en consecuencia, cuando un hecho no ha quedado probado, el juez debe establecer qué parte perderá el pleito con base en la norma sustantiva que rige el caso, pues es ésta la que establece qué parte debe probar qué hechos (Taruffo, 2008). Así pues, el onus probandi sólo entra en juego cuando hay inexistencia probatoria, pero no cuando hay demostración de 
Ios hechos. A este respecto, el Tribunal Supremo español admite que la carga de probar hay que combinarla con la facilidad de probar. Así, cuando se determina a quién le era más fácil probar y no lo hizo, a esa parte la misma facilidad obliga a atribuirle la carga de la prueba (De Ángel, 1999).

Una vez revisados los últimos fallos condenatorios del Consejo de Estado, sumado a todas estas reflexiones, sobre todo la atinente a la nueva tendencia del Consejo Estado, de la cual se percibe su ansioso deseo por desterrar la falla "presunta" $y$ en su lugar imponer la teoría de la falla "probada" como principio general en materia de responsabilidad médico-asistencial, llevan a un importante cuestionamiento en relación con la manera como esta corporación concibe la naturaleza jurídica de la presunción y es que al parecer el alto Tribunal considera la presunción como un "medio" de prueba y no como un "método" de prueba.

En efecto, partiendo de los estudios realizados por esta destacada doctrina (Álvarez, 2007), en el sentido de que no se debe confundir el concepto "técnico procesal" de presunción, con el concepto "vulgar" de presunción también presente en el lenguaje jurídico; además, que no se debe confundir la presunción con otros mecanismos lógicos, dotados de una virtualidad similar a la presunción, se comparte la conclusión de que la presunción es un "método de prueba"1. Específicamente la presunción judicial, aunque no es un medio de prueba, sirve para la misma finalidad que los medios de prueba, ya que su formulación entra de lleno en la formación de la convicción sobre los hechos relevantes para decidir sobre la pretensión procesal (Ortells, 2000). La presunción es un "método deductivo" que lleva a dar como probados hechos con respecto a los cuales no existen pruebas directas. La presunción es pues, en suma, un "método" o actividad lógica de inferencia

1 En sentido contrario la doctrina colombiana considera que la presunción o indicio es un medio de prueba (López, 2001). de nuevos hechos, que se realiza al momento de valorar la prueba, a partir de los hechos probados (admitidos, indicios) ya fijados en el juicio.

Esta manera de concebir la presunción implica su reconocimiento como institución distinta a las reglas sobre la carga de la prueba, en el sentido de que las presunciones sí inciden en la carga de la prueba, pero sólo alterando su objeto, y las reglas sobre la carga de la prueba, por su parte, como antes se señaló, no sólo definen el ámbito de la responsabilidad probatoria de las partes, sino que también aportan la regla de juicio a la hora de dictar sentencia, a fin de evitar que el juez, al final del proceso, se ampare en la falta de prueba para negarse a resolver.

En consecuencia, se podría interpretar que no es que el Consejo de Estado esté cambiando de postura, sino más bien, está tratando de corregir su concepción en torno a la presunción. En efecto, como arriba se indicó, existen figuras afines, más o menos próximas y, con frecuencia, confundidas con las presunciones judiciales, entre ellas, la "intervención jurisprudencial en las reglas sobre la carga de la prueba", "las meras deducciones" y el "principio de expansión en la apreciación de la prueba en beneficio del más débil" al que se da aplicación en aquellos eventos en que la dificultad de la prueba, pone en condiciones de inferioridad al demandante, contradiciendo los principios de equidad (Álvarez, 2007). Se trata de construcciones lógicas que afectan, sin duda, la carga de la prueba, aunque no siempre bajo el razonamiento lógico que en estricto sentido implica una presunción judicial. Nos hallamos frente a otro tipo de razonamientos deductivos que llevan, igualmente, a la definición de los hechos probados.

En estos casos, la incidencia en la carga de la prueba no tiene lugar a través de una presunción de culpa, que -como se indicó- supondría una modificación en el "objeto" de la prueba, más específicamente, en el "tema" de la prueba. En 
efecto, a través de la presunción se produce una alteración en el objeto de la carga de la prueba, pues la parte favorecida con la presunción debe probar, no los presupuestos propios de la consecuencia jurídica, sino los presupuestos de la presunción. Así, sólo de manera impropia se puede decir que la presunción supone una "inversión" de la carga de la prueba. Las presunciones no afectan el principio general del onus probandi, sino que sólo facilitan la situación procesal de la parte favorecida con ellas.

Entonces, la presunción altera en menor medida el equilibrio de las partes, que las normas de inversión de la carga de la prueba, con las que una de ellas resulta exonerada o sufre una atenuación en su carga probatoria, sin embargo, la otra resulta perjudicada en su situación procesal, teniendo en cuenta que su carga se mantiene inalterada. Así pues, a través de estas otras clases de razonamientos deductivos, establecidos inadecuadamente como una "presunción", no se da la estructura propia de esta figura como método indirecto que permite llegar al hecho presunto a partir del hecho conocido.

Todo esto nos podría llevar a la deducción que en muchos eventos el Consejo de Estado no hace uso de la presunción judicial, sino de aquellas figuras afines, más o menos próximas y con frecuencia confundidas con las presunciones judiciales. Toda esta conceptualización inadecuada en relación con la naturaleza de las presunciones, tal vez explique que el Consejo de Estado esté ejecutando esa conducta tan reconocida en los jueces de negarse a exteriorizar que han obtenido su convicción con base en presunciones, enmascarándolas a través del recurso a la apreciación conjunta de la prueba. Una clara expresión de la desconfianza hacia la presunción (Serra, 1981), que lleva a que los jueces, aunque funden su juicio sobre presunciones, raramente reconozcan de manera expresa haber acudido a ésta; tendencia que resulta contraria a las mismas presunciones, al desdibujar el juicio presuntivo, pero que en la práctica no implica una menor utilización de ellas.

En consecuencia, si se reconoce que nuestro máximo Tribunal de lo Contencioso Administrativo recurre a figuras afines a las presunciones, que también son aplicadas en el ámbito internacional, debería, sin temor alguno, explicitar el razonamiento presuntivo; de igual forma, debería acabar de una vez por todas con ese "miedo a las presunciones" (Álvarez, 2007), teniendo en cuenta que existen múltiples motivos que justifican el recurso a ellas en la práctica judicial como, por ejemplo, la potencial inferioridad de una de las partes en el proceso en relación con los hechos por probar y a fin de dotar de mayor virtualidad al principio de igualdad o equilibrio procesal, pues éste, en definitiva, es el que garantiza la justicia de la decisión, es decir, una sentencia que no esté condicionada por el mayor poder o mejor posición de una de las partes (Moreno \& Cortés, 2005).

Así pues, "la manifestación y expresión del razonamiento deductivo debe contribuir a encontrar una mayor seguridad en este método probatorio, y un menor miedo por parte del juzgador a afirmar de manera expresa que, mediante presunciones, tiene determinado hecho por probado". Pero, eso sí, sin desconocer que es indiscutible que el recurso a la presunción de falla del servicio médico oficial no es automático ni se debe aplicar sin reflexión, lógica, ni análisis del caso concreto. El juez debe tener muy en claro que lo que no puede hacer es intentar suplir la falta de iniciativa probatoria de las partes; además, que la presunción no puede sustituir a la prueba directa, para el caso de que ésta exista. Por tanto, el juez acudiría a las reglas del onus probandi a falta tanto de prueba directa como de prueba por presunciones.

En suma, se espera que haciendo gala de su justa doctrina, construida después de años de reflexión, el Consejo de Estado, coherente con los adelantos mundiales del derecho de la responsabilidad, 
continúe por la senda de la protección de la parte débil, que en este caso viene a estar representada por el demandante (paciente-víctima), a través del recurso a las presunciones entendidas en su sentido técnico, es decir, como un método de prueba indirecto, en el cual el punto de partida es un hecho base (hecho indicio), probado o admitido, sobre el cual opera el nexo lógico, basado en un juicio de probabilidad cualificada que lleva a la afirmación del hecho presunto. En este caso, por tratarse de una presunción, se debe tener en cuenta que el médico puede dirigir su actividad probatoria hacia el debilitamiento de la conclusión o deducción de que unos daños como los producidos no pueden tener otra causa razonable que la conducta negligente del médico, por ejemplo, si aporta indicios de que las condiciones de salud del paciente pueden explicar las complicaciones esperadas (Álvarez, 2007); otra cosa sería, cuando se trata de una simple inversión de la carga de la prueba, pues aquí el médico sí está obligado a probar, aportando plena certeza de que no ha sido su conducta la causante de los daños, lo cual puede justificar las dificultades probatorias que tanto reclaman algunos críticos opositores.

Estas posibilidades se deben diferenciar de aquellos casos en los cuales lo que hace el juez es simplemente tomar su decisión, sin acudir a la presunción, sino con base en la valoración crítica de pruebas directas presentes en el proceso y apreciadas en conjunto, que dista mucho de la mecánica del método presuntivo, pero que no es razón para negar la presunción de falla, incluso, como principio general, teniendo en cuenta que dadas las peculiaridades de la responsabilidad médica, la convierten en un ámbito apropiado para definir los hechos a través del recurso a las presunciones.

\section{Avances del derecho de la responsabilidad a nivel mundial}

A nivel mundial el derecho de la responsabilidad día a día sufre adelantos que pretenden mejorar sus reglas adecuándolas a las nuevas realidades y necesidades sociales. Por ejemplo, en Europa la propuesta del grupo de Tilburg European Group on Tort Law, luego de varios años de trabajo dirigidos a construir un derecho europeo de la responsabilidad civil, con principios comunes aunque no vinculantes, acordó los Principios de Derecho Europeo de la responsabilidad civil" (Martín-Casals, 2005), en los cuales, teniendo en cuenta la adopción por parte de varios códigos civiles europeos del principio de responsabilidad por culpa presunta (BusneIIi, 2006), se planteó finalmente la posibilidad de "invertir la carga de la prueba de la culpa".

A su vez, el campo específico de la responsabilidad médica se ha caracterizado por un importante proceso de evolución, los diversos sistemas jurídicos trabajan por la consagración de instituciones que garanticen una posición más favorable para el paciente víctima de daños, teniendo en cuenta la reconocida e indiscutible posición de inferioridad en la que se encuentra en relación con el profesional. Por ejemplo, en Italia se realizó el paso de una responsabilidad por culpa probada a la presunción de culpa, como consecuencia de una reinterpretación del art. 2043 del Código Civil, dependiendo de que el acto médico pudiera o no catalogarse como "de fácil o difícil ejecución", garantizando de este modo una tutela resarcitoria más amplia y completa (Ponzanelli, 1992). Por su parte, en Francia, en el ámbito público, la falta simple permite comprometer la responsabilidad del servicio público a través del juego de presunciones, la jurisprudencia considera la técnica de la presunción como una técnica suficiente para lograr la protección no sólo de las víctimas, sino también, de los principios de la responsabilidad hospitalaria fundada en la culpa (Guettier, 2003). En cambio, en el ámbito privado dentro de ciertas hipótesis se recurre a la teoría de la faute virtuelle (culpa virtual), a cuya construcción han recurrido los jueces civiles para remediar las dificultades de prueba de la culpa, en presencia de ella, la explicación causal del resultado implica la culpa, declarándose la responsabilidad sin que sea 
totalmente identificada la relación de causalidad (Dorsner-Dolivet, 2006).

Por otra parte, si bien en los países de mayor tradición romanista la regla res ipsa loquitur ("los hechos hablan por sí mismos") no ha sido de uso frecuente, aunque se advierte un uso cada vez mayor, en Estados Unidos se recurre al uso de este principio de manera reiterada y se viene aplicando en los procesos de responsabilidad médica como una manera de romper la llamada "conspiración del silencio", que hace casi imposible conseguir un médico que testifique en contra de otro, produciendo injusticia en un sinnúmero de casos de mala práctica médica. En la doctrina judicial estadounidense se han fijado las tres condiciones necesarias para la aplicación de este principio, a saber: que el accidente sea de tal naturaleza que ordinariamente no ocurra en ausencia de negligencia por parte de alguna persona; que sea causado por una agencia o instrumento dentro del control exclusivo del demandado; que no pueda haber sucedido debido a acción voluntaria alguna o negligencia del demandante (Vásquez, 1995). Este principio

\section{[...] permite inferir no sólo la causalidad, sino también la culpa; cuando se amputa la pierna equivocada, o se opera de fimo- sis en lugar de amigdalitis, o se olvida una gasa o pinzas en la zona intervenida, o el odontólogo deja caer una pieza dental dentro de la tráquea del paciente, escasa o nula prueba requiere la culpa. Lo mismo sucede cuando el cirujano, en lugar del apéndice, corta otra parte del intestino, o el ginecólogo deja materia ovular en el curso de un raspado (Santos, 2004).}

También se ha aplicado cuando se ha quemado al paciente con rayos infrarrojos, cuando se producen daños como consecuencia de intervenciones quirúrgicas menores o anestesias simples, o por rotura de un diente del paciente cuando estaba anestesiado, o fractura de la mandíbula durante una extracción de dientes, o lesión de un nervio durante la aplicación de una inyección hipodér- mica, lo que no ocurre normalmente (Lorenzetti, 2005). En suma, en la jurisprudencia norteamericana el conocimiento común entre los legos, que el accidente ordinariamente no hubiera ocurrido sin negligencia, ha sido considerado suficiente para invocar la teoría y permitir una inferencia o deducción de negligencia en casos en los que hay objetos que se han dejado en el cuerpo del paciente durante la cirugía; la producción de daños en una parte saludable del cuerpo dentro del área de tratamiento o a una parte remota del área de tratamiento, bien sea que esté saludable o no; la remoción equivocada de una parte del cuerpo cuando otra parte fue la intencionada; la caída de dientes por la tráquea; quemaduras por lámparas calentadoras, radiografías -especialmente si son para propósitos diagnósticos-, vaporizantes, productos químicos, lámparas de mesa; infecciones resultantes de instrumentos sin esterilizar; la negativa de tomar radiografías para diagnosticar posibles fracturas; la incapacidad que ha resultado directamente de una inyección de drogas en el cuerpo y las explosiones de gases anestésicos (Vásquez, 1995).

Vistos de manera somera, sólo algunos de los tantos adelantos mundiales en la materia podemos con certeza concluir que Colombia no puede permanecer inmóvil y rezagada frente al latente y enorme desarrollo del derecho de la responsabilidad a nivel mundial donde, desde años atrás, quedó superada la discusión frente a la consagración de nuevas formas protectoras para la parte débil, para la parte en situación de inferioridad dentro de las relaciones jurídicas.

\section{CONCLUSIÓN}

Si bien a lo largo del texto se han venido destacando distintas conclusiones con respecto a la reflexión adelantada, no sobra reiterar que es necesario que el Consejo de Estado siga avanzando hacia la consagración de fórmulas modernas de protección de la persona y de este modo se integre armóni- 
camente a los avances mundiales. La responsabilidad no es un universo estático, requiere de una continua evolución, por tanto, teniendo en cuenta que de ordinario el paciente no tiene medios directos para precisar las actuaciones médicas $y$ sanitarias, es razonable que el Consejo de Estado tome sin miedos y prevenciones la senda de la presunción, pues, a pesar de la existencia de otros mecanismos lógicos, dotados de una virtualidad similar a la presunción, ésta se convierte en un método apropiado para definir los conflictos de responsabilidad médica.

La conclusión general a la que se puede llegar es que al parecer el Consejo de Estado no está viviendo en estricto sentido un retroceso, sino que más bien, debido a su imprecisa concepción en torno a las presunciones, en la práctica recurre no sólo a la prueba directa, sino además, a aquellas figuras afines, más o menos próximas y que con frecuencia son confundidas con las presunciones mismas, pero que en el fondo se trata de razonamientos deductivos, establecidos inadecuadamente como una presunción.

Teniendo en cuenta que dadas las peculiaridades de la responsabilidad médica ésta se convierte en un ámbito apropiado para definir los hechos a través del recurso a las presunciones, es preciso que el Consejo de Estado no ejecute más esa conducta tan reconocida en los jueces de negarse a exteriorizar que han obtenido su convicción con base en presunciones, como una clara expresión de la desconfianza hacia la figura, tendencia que, de suyo, resulta contraria a las presunciones mismas, al desdibujar su juicio presuntivo.

Nuestro alto Tribunal de lo contencioso administrativo debería, sin temor alguno, explicitar el razonamiento presuntivo, pero eso sí sin desconocer que el recurso a la presunción de falla del servicio médico oficial no es automático, ni se debe aplicar sin reflexión, lógica, ni análisis del caso concreto, además, teniendo muy en claro que lo que no se puede hacer es intentar suplir la falta de iniciativa probatoria de las partes, ni sustituir la prueba directa para el caso de que ésta exista.

\section{REFERENCIAS}

Álvarez, P. (2007). La prueba por presunciones. Granada: Comares.

Busnelli, F. (2006). Las fronteras europeas de la responsabilidad civil. En J. De los Mozos, \& C. Soto, Responsabilidad civil. Derecho de daños. Teoría general de la responsabilidad civil (pp. 17-31). Lima: Grijley.

Carrasco, A. (2006). Responsabilidad médico sanitaria: Un modelo de fundamentación a la luz de la jurisprudencia española. En J. De los Mozos, \& C. Soto. Responsabilidad civil. Dereho de daños. Responsabilidad de los profesionales, de las personas jurídicas y del Estado (pp. 275-310.). Lima: Grijley.

Consejo de Estado. 2 de noviembre de 1960. CP. Carlos Gustavo Arrieta.

Consejo de Estado, Sección tercera, 13 de julio de 2005. CP. Ramiro Saavedra.

Consejo de Estado, Sección tercera, 14 de febrero de 1992. CP. Carlos Betancur Jaramillo.

Consejo de Estado, Sección tercera, 15 de junio de 2000. CP. María Elena Giraldo.

Consejo de Estado, Sección tercera, 17 de agosto de 2000. CP. Alier Eduardo Hernández.

Consejo de Estado, Sección tercera, 22 de marzo de 2000. CP. Ricardo Hoyos.

Consejo de Estado, Sección tercera, 22 de mayo de 1992. CP. Juan de Dios Montes Hernández.

Consejo de Estado, Sección tercera, 24 de octubre de 1990. CP. Gustavo de Greiff. 
Consejo de Estado, Sección tercera, 26 de marzo de 1992. CP. Julio César Uribe.

Consejo de Estado, Sección tercera, 26 de marzo de 2008. CP. Ruth Stella Correa.

Consejo de Estado, Sección tercera, 27 de marzo de 1987. CP. Carlos Betancur Jaramillo.

Consejo de Estado, Sección tercera, 3 de abril de 1997. CP. Carlos Betancur Jaramillo.

Consejo de Estado, Sección tercera, 30 de agosto de 2007. CP. Mauricio Fajardo.

Consejo de Estado, Sección tercera, 30 de julio de 1992. CP. Daniel Suárez.

Consejo de Estado, Sección tercera, 7 de octubre de 1999. CP. María Elena Giraldo.

Corte Constitucional, C-333 del 1 de agosto de 1996.

Corte Constitucional, SU-837 del 9 de octubre de 2002.

Corte Suprema de Justicia, Casación Civil, 21 de agosto de 1939. MP. Hernán Salamanca.

Corte Suprema de Justicia, Casación Civil, 30 de junio de 1962. MP. José J. Gómez.

De Ángel, R. (1999). Responsabilidad civil por actos médicos. Problemas de prueba. Madrid: Civitas.

Díaz-Regañón, C. (1996). El régimen de la prueba en la responsabildiad civil médica. Pamplona: Aranzadi.

Dorsner-Dolivet, A. (2006). La responsabilité du médecin. Paris: Economica.

Fernández, M. (2008). La responsabilidad médica. Problemas actuales. Bogotá: Ibañez.
Gil, E. (1995). La falla del servicio en el campo médico y hospitalario. Revista Responsabilidad Civil y del Estado, 23-35.

Guettier, C. (2003). Faute civile et faute administrative. Responsabilité civile et assurance , 66-74.

Hoyos, R. (1999). Balance jurisprudencial del Consejo de Estado en materia de responsabilidad a partir de la constitución política de 1991. Responsabilidad civil y del Estado, 97-135.

Lleras, C., \& Tangarife, M. (1996). Constitución Política de Colombia: origen, evolución, vigencia. Bogotá: Diké.

López, H. (2001). Procedimiento civil. Pruebas. Bogotá: Dupre Editores.

Lorenzetti. (2005). Responsabilidad civil de los médicos. Lima: Grijley.

Martín-Casals, M. (2005, 17 de octubre). Líneas generales de los "principios de derecho europeo de la responsabilidad civil. Recuperado el 15 de febrero de 2009, de: http://asociacionabogadosrcs.org.

Moatti, L. (1988). En I'absence de faute du médecin, n'existe-t-il pas un préjudice ? Gazette $d u$ Palais, 672-679.

Moreno, V. \& Cortés, V. (2005). Introducción al Derecho Procesal. Valencia: Tirant lo Blanch.

Navia, F. (2000). La responsabilidad extracontractual del Estado a la luz del artículo 90 de la Constitución Política. Revisa de Derecho Privado , 211-231.

Ortells, M. (2000). Derecho procesal civil. Pamplona: Arazadi.

Parra, M. (2004). Carga de la prueba en la responsabilidad médica. Bogotá: Doctrina y Ley. 
Peláez, M. (2003). Algunos aspectos de la evolución jurisprudencial sobre responsabilidad patrimonial del Estado y civil de los particulares por la prestación de servicios de salud. Responsabildiad civil y del Estado, 89-116.

Ponzanelli, G. (1992). La responsabilità civile. Profili di diritto comparato. Bologna: Il Mulino.

Rocha, A. (1941). De la prueba en derecho. Bogotá: Librería Siglo XX.

Rocha, A. (1967). De la prueba en derecho. Bogotá: Lerner.

Rocha, A. (1967). De la prueba en derecho. Bogotá: Lerner.

Santos, J. (2006). Instituciones de responsabilidad civil. Bogotá: Editorial Pontificia Universidad Javeriana.

Sarmiento, M. (2001). La teoría objetiva de la responsabilidad en el artículo 90 de la Constitución. Revista de Derecho Privado, 35-49.
Serra, M. (1981). Comentarios al Código Civil y Compilaciones Forales. Madrid: Edersa.

Suárez, D. (1997). Responsabilidad médica y Consejo de Estado. Revista del Instituto Nacional de Medicina Legal de Colombia, 72.

Suescún, J. (2004). Derecho privado. Estudios de derecho civil y comercial contemporáneo. Bogotá: Legis.

Tamayo, J. (2003). Rapport colombien (I). En AA.W., La responsabilitè. Aspects nouveaux (Journées panaméennes) (pp. 245-254). Paris: L.g.d.j.

Tamayo, J. (2003). Sobre la prueba de la culpa médica. En derecho civil y administrativo. Análisis doctrinal y jurisprudencial. Medellín: Dike.

Taruffo, M. (2008). La prueba. Madrid: Marcial Pons. Vásquez, R. (1995). Prueba de la culpa médica. Medellín: Dike. 